\title{
Combined Experimental and Numerical Investigation of the ECN Spray G under Different Engine-Like Conditions
}

Davide Paredi, Tommaso Lucchini, Gianluca D'Errico, and Angelo Onorati Politecnico di Milano

Alessandro Montanaro and Luigi Allocca Istituto Motori CNR

Roberto lanniello Università di Cassino

Citation: Paredi, D., Lucchini, T., D'Errico, G., Onorati, A. et al., "Combined Experimental and Numerical Investigation of the ECN Spray G under Different Engine-Like Conditions," SAE Technical Paper 2018-01-0281, 2018, doi:10.4271/2018-01-0281.

\section{Abstract}

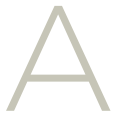

detailed understanding of Gasoline Direct Injection (GDI) techniques applied to spark-ignition (SI) engines is necessary as they allow for many technical advantages such as increased power output, higher fuel efficiency and better cold start performances. Within this context, the extensive validation of multi-dimensional models against experimental data is a fundamental task in order to achieve an accurate reproduction of the physical phenomena characterizing the injected fuel spray. In this work, simulations of different Engine Combustion Network (ECN) Spray G conditions were performed with the Lib-ICE code, which is based on the open source OpenFOAM technology, by using a RANS Eulerian-Lagrangian approach to model the ambient gas-fuel spray interaction. Foremost, the main scope of the activity was to identify the most accurate numerical set-up in terms of atomization ad secondary break-up models, thanks to a validation of the computed results against experimental data available for the ECN Spray G baseline condition. Specifically, attention was focused on spray penetration along with an analysis of spray morphology and effects of plume-to-plume interaction. Afterwards, the reference set-up was tested and validated under different operating conditions, characterized by detailed experimental measurements specifically provided for this work. In particular, Mie scattering and Schlieren techniques allowed the quasi-simultaneous acquisition of both vapor and liquid penetrations, while a customized imageprocessing procedure, developed in Matlab environment, was used for the outline of the spray contours of both fuel phases to measure the parameters characterizing the jet development. A robust reference numerical set-up was identified, capable to reproduce with good accuracy the injection process of a multi-hole GDI spray under the wide range of tested operating conditions.

\section{Introduction}

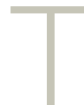

he efficiency of internal combustion engines significantly increased during the last decade, however further developments are required to accomplish new regulations in terms of pollutant emissions and fuel consumption. Due to their lower manufacturing costs, relatively simplified after-treatment systems, easy integration with hybrid technology and capabilities to operate with alternative fuels, spark-ignition engines (SI) appear to be the best candidates as a reference powertrain technology for passenger cars. Within this context, research activities are currently carried out about electrification, new control strategies, fuel injection and combustion systems. In particular, the optimization of the fuel injection process is fundamental to prepare an air-fuel mixture capable to promote an efficient combustion, allowing for reduced pollutant emissions and fuel consumption. Specifically, the concept of direct injection (DI) applied to SI engines is to this day studied with renewed interest $[1, \underline{2}, \underline{3}]$ because it allows for reduction of knock effects, better coldstart performances and overall higher efficiency. However, since full outer spray angle values for gasoline direct injection (GDI) sprays are narrower compared to diesel jets (from $60^{\circ}$ to $90^{\circ}$ compared to the $140^{\circ}-160^{\circ}$ range of diesels [4]), it was necessary to carry out experimental works to study the effects of the GDI spray evolution on fuel consumption and pollutant emissions [ [ $\underline{]}$ under both non-evaporating [ $[\underline{6}]$ and engine-like conditions $[\underline{7}, \underline{8}, \underline{9}]$. Factors affecting the spray collapse $[\underline{10}, \underline{11}]$ as well as flash boiling phenomena $[\underline{12}, \underline{13}]$ were also investigated.

Within this context, achieving an accurate modeling of the spray development during a direct injection process still represents a complex task in Computational Fluid Dynamics (CFD). On this basis, the Engine Combustion Network (ECN) allowed for a specific multi-hole gasoline injector known as Spray G to represent an available benchmark both for experimental and numerical validations. During the years, different 
CFD simulations were performed on the Spray G geometry, proposing detailed modeling of the internal nozzle flow [14] under both flashing and non-flashing conditions $[\underline{15}, \underline{16}, \underline{17}]$. Furthermore, LES simulations were deployed for the injection modeling [18] and they were also coupled with DNS investigation of the spray near-nozzle primary break-up [19], while effects of ambient temperature and ambient density on plume interaction and vaporization were experimentally investigated $[\underline{4}, \underline{10}, \underline{20}]$, providing a consistent dataset for the most recent available RANS and LES numerical validations [21].

In this work, the authors intended to provide a comprehensive numerical methodology which could be flexible and accurate enough to perform RANS simulations of multi-hole GDI injectors [22] under a wide range of operating conditions. ECN multi-hole Spray G injector was used as the reference geometry. Different combinations of numerical set-up in terms of spray angles, atomization and secondary break-up models were calibrated, tested and validated under the baseline Spray G condition. Afterwards, the most accurate set-up was tested under a wide range of engine-like operating conditions specifically thought for this work, whose experimental penetration and morphology data were provided by Istituto Motori CNR of Napoli by means of Mie scattering and Schlieren optical techniques.

\section{Experimental Background}

The Spray G injector [22] is characterized by a 8 -hole geometry shown in Figure 1(a), whose most important specifications are reported in Figure 1(b) and Table 1. The purpose of the research performed on the Spray G geometry is to reproduce the injection phase during an engine-like compression stroke without spark-ignition (non-reacting mixture condition).

According to the ECN convention, the axial dimension is defined with reference to the tip of the injector, while

\section{FIGURE 1 8-hole Spray G geometry [22]}

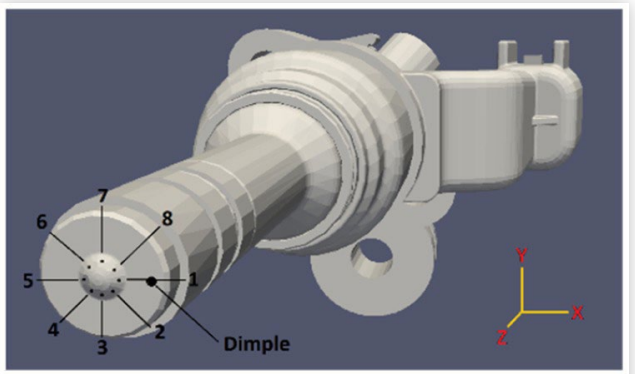

(a) Spray G injector

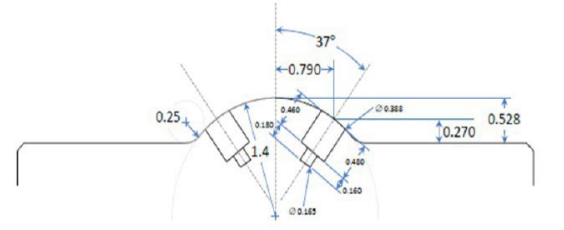

(b) Main geometrical specifications
Figure 2 reports how parameters such as the "drill angle", the "plume direction" $(P D)$, the "plume cone angle" $(P C A)$ and the "full outer spray angle" are measured. In particular, with reference to the injector axis, the "drill angle" was found to be equal to $37^{\circ}$ for the Spray G geometry [21] .

Patternation data analysis [23] allowed to understand that an actual deflection of the spray plumes towards the injector axis exists, leading to a difference between the concepts of "drill angle" and "plume direction", with the latter decreasing towards a value of $33^{\circ}$. A smaller "plume direction" compared to the "drill angle" was also observed with experimental x-ray radiography measurements, performed at $2 \mathrm{~mm}$ from the injector tip [24], which reported a reduction to $34^{\circ}$.

Within this context, standard operating conditions were chosen by the ECN to ensure consistency between experimental and numerical activities and to create a wide literature dataset. Table 2 reports the specifications of the Spray G baseline condition.

The reference mass flow rate profile was measured by Scott Parrish at GM R\&D and also at CMT-Motores Termicos [25]. The total amount of injected fuel mass is $10 \mathrm{mg}$, with electronic and hydraulic durations respectively of $680 \mu \mathrm{s}$ and a $780 \mu \mathrm{s}$.

The wide range of engine-like experimental conditions, specifically thought for this work, were investigated by Istituto Motori CNR of Napoli by injecting iso-octane $\left[\rho=690 \frac{\mathrm{kg}}{\mathrm{m}^{3}}\right.$ at $\left.25^{\circ} \mathrm{C}\right]$ in a heated constant-volume pressurized vessel. Three large windows ( $80 \mathrm{~mm}$ in diameter) are placed

TABLE 1 Spray G injector charcateristics

\begin{tabular}{|c|c|}
\hline Fuel & Iso-octane \\
\hline Ambient gas & Pure nitrogen (inert) \\
\hline Injector type & Delphi solenoid-activated \\
\hline Nozzle type & Valve-covered orifice (VCO) \\
\hline Number of holes & 8 (equally spaced) \\
\hline Nozzle shape & Step hole \\
\hline $\begin{array}{l}\text { Orifice diameter } \\
\text { (specification) }\end{array}$ & $0.165 \mathrm{~mm}$ \\
\hline Orifice diameter (measured) & $0.175 \mathrm{~mm}$ \\
\hline Orifice length & $0.16-0.18 \mathrm{~mm}$ \\
\hline Step diameter (specification) & $0.388 \mathrm{~mm}$ \\
\hline Step diameter (measured) & $0.400 \mathrm{~mm}$ \\
\hline Orifice drill angle & $37^{\circ}$ relative to the nozzle axis \\
\hline Full outer angle & $80^{\circ}$ \\
\hline
\end{tabular}

FIGURE 2 Adopted conventions for spray angles [21]

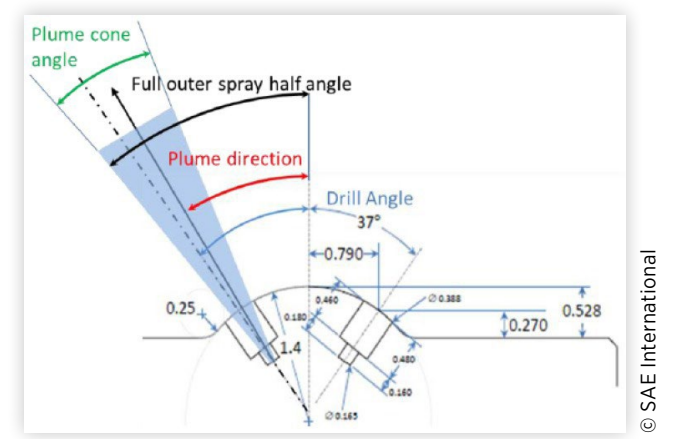

(c) 2018 SAE International. All Rights Reserved. 
TABLE 2 Spray G baseline operating condition

\begin{tabular}{|c|c|}
\hline Injection pressure & 200 bar \\
\hline Fuel temperature & $363.15 \mathrm{~K}$ \\
\hline Ambient temperature & $573.15 \mathrm{~K}$ \\
\hline Ambient density & $3.5 \frac{\mathrm{kg}}{\mathrm{m}^{3}}$ \\
\hline Injected mass & $10 \mathrm{mg}$ \\
\hline Injection duration & $780 \mu \mathrm{s}$ \\
\hline
\end{tabular}

FIGURE 3 Schematic of the injector and "plume directions" [22]

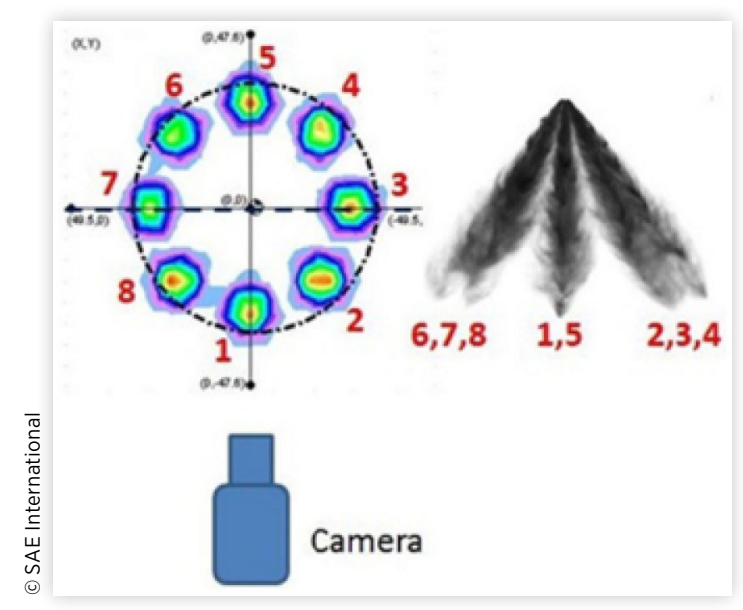

surrounding the cylindrical test chamber in an orthogonal way, with the layout giving full optical access to the internal test section of the combustion chamber. Figure 3 shows the schematic of injector and "plume directions" with respect of the camera line-of-sight. The eight plumes were distributed in three groups within a spray cone angle of $80^{\circ}$ and a bent angle of $37^{\circ}$.

The fuel was injected through a common rail system varying the injection pressure from 5.0 to $20.0 \mathrm{MPa}$ while the injection timing was set at $680 \mu \mathrm{s}$ for all the tested conditions. Fuel spray images were acquired at ambient gas temperatures ranging from $333.15 \mathrm{~K}$ to $573.15 \mathrm{~K}$. Four values of ambient gas pressure, corresponding to ambient densities of $0.2,0.5$, 1.0 , and $3.5 \frac{\mathrm{kg}}{\mathrm{m}^{3}}$, were investigated at each set temperature.

The ambient temperature control system was composed by electrical heaters, temperature controller and sensor. Electrical heaters were used to increase the temperature of the gas in the test chamber up to the required value. The inlet gas was heated homogenously because the resistances were twined covering all the internal walls of the test chamber. The inner part of the test chamber was provided with an insulating layer to reduce heat losses from the gas. This layout ensured a homogenous temperature of the gas in the whole chamber, which was set by means of the combination of controller and sensors acting on the electrical heaters. The fuel was injected through a common rail device heated by an electrical resistance and controlled in temperature by a J-type thermocouple. A governor managed the temperatures of nozzle and fuel via a remote computer, and both of them were kept at $363.15 \mathrm{~K}$.

A high-speed C-Mos camera, allocated in a combined Mie scattering/Schlieren optical configuration, acquired pictures of the liquid and vapor phases of the evolving sprays in a quasi-simultaneous fashion and using the same optical path. A pulsed LED (Light Emitting Diode) Omicron LED MOD V2, $455 \mathrm{~nm} / 450 \mathrm{~mW}$ was used as Schlieren light source with the traditional Z-folded configuration, while a highfrequency copper-vapor laser provided illumination for Mie scattering at the rate of $12.5 \mathrm{kHz}$. Images were acquired by a $90 \mathrm{~mm}$ objective with a rate of 25,000 frames per second and an image resolution of $384 \times 352$ pixels, realizing a spatial resolution of $4.5 \frac{\text { pixel }}{\mathrm{mm}}$. High-speed Mie scattering imaging was used to visualize the liquid phase, while the corresponding Schlieren was employed to visualize both the liquid and vapor phases. The combined optical technique was well suitable to capture the peculiarities of the different thermodynamic phases of the fuel and was sensitive to the governing parameters (ambient temperature and density). More details of the so-called frame-straddling configuration, as well as of the adopted optical setup, were respectively reported in $[\underline{26}, \underline{4}, \underline{27}]$.

The discernment of the liquid core, the more or less finely atomized fluid and the vapor phases were selected applying a customized algorithm of image processing developed under Matlab platform. Schlieren and Mie-scattering images were treated differently due to the diverse luminosity of the spray image. A batch procedure of background subtraction, gamma correction, morphology filtering, and image segmentation was applied on the Schlieren and Mie scattering images in order to better outline the contours of both vapor and liquid phases. Finally, an automatic procedure extracted the trends for the characterization of the macroscopic spray structure as a function of ambient pressure and temperature. A detailed description of the adopted image processing procedure was reported in [27].

\section{Numerical Background}

Simulations were performed with the open-source OpenFOAM CFD code coupled with the Lib-ICE, a set of libraries specifically thought for internal combustion engines computations, developed and validated by the ICE Group of Politecnico di Milano. A RANS approach was chosen along with the standard $\mathrm{k}-\varepsilon$ model for turbulence, while the modeling of the spray and of its interaction with the surrounding gas was performed thanks to a Eulerian-Lagrangian coupling [28]. Once the liquid fuel leaves the injector nozzle, phenomena of atomization, secondary break-up, heat transfer and evaporation occur, leading to fuel vaporization and mixing with the ambient gas. Within this context, the work was focused on providing a combination of atomization and break-up models which could be capable to predict with a good level of accuracy a multi-hole 
spray behavior under a wide set of engine-like operating conditions.

The Huh-Gosman model $[\underline{29}, \underline{30}]$ was used to predict the atomization of the liquid jet and it was respectively coupled with the Reitz-KHRT [31] and the Reitz-Diwakar [32] models for secondary break-up.

The computational domain was characterized by an initial cell size of $4 \mathrm{~mm}$ and by an automatic mesh refinement (AMR) procedure, adopted to locally refine the grid where fuel mass was found. The refinement procedure was based on the volumetric scalar field Yttf, which is calculated as the overall fuel mass fraction found in the domain by taking into account both the liquid and vapor components. Minimum cell sizes of $1 \mathrm{~mm}$ or of $0.5 \mathrm{~mm}$ were adopted, coherently with the average mesh refinement level used for GDI full-cycle simulations. As Figure 4 shows, it was mandatory to ensure results consistency between vessel and full-cycle simulations, for which the AMR approach is not generally used.

Table 3 reports the main specifications of the numerical set-up.

Effects of "plume direction" and "plume cone angle" are fundamental in terms of spray morphology and efficiency of the air-fuel mixing process. In this regard, on the basis of the latest experimental investigations performed on the Spray G nozzle geometry $[\underline{20}, \underline{15}]$ and, more in general, with reference

FIGURE 4 Validation of spray targeting consistency between cases with and without AMR approach

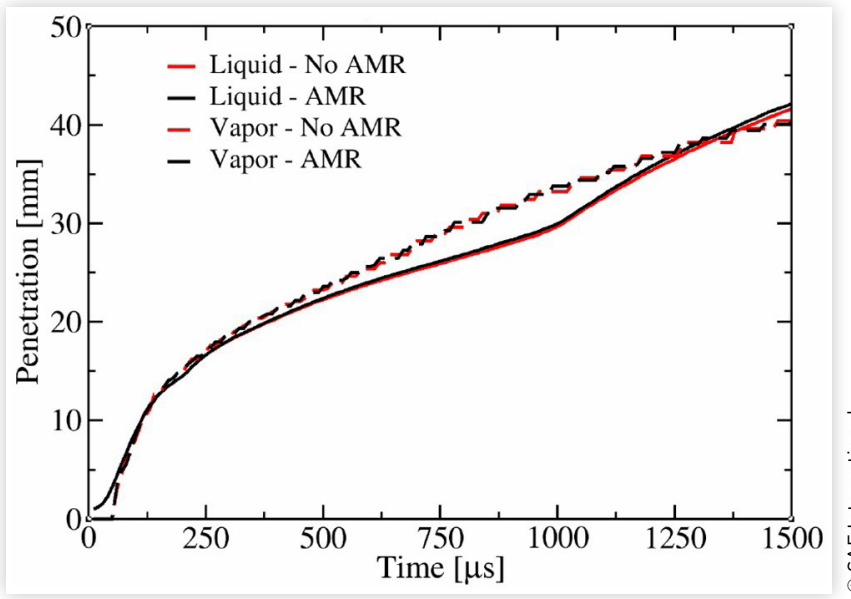

TABLE 3 Adopted numerical models

\begin{tabular}{|l|l|}
\hline CFD code & OpenFOAM with LibICE \\
\hline $\begin{array}{l}\text { Turbulence model } \\
\text { Injection model }\end{array}$ & RANS standard k- $\varepsilon$ \\
\hline Atomization model & Lagrangian Huh \\
\hline Secondary break-up & Huh-Gosman \\
\hline Evaporation model & Reitz-KHRT or Reitz-Diwakar \\
\hline Heat transfer & $\begin{array}{l}\text { Based on Spalding mass } \\
\text { transfer number }\end{array}$ \\
\hline Type of mesh refinement & Ranz-Marshall \\
\hline Base cell size & Adaptive (AMR) \\
\hline Minimum cell size & $4 \mathrm{~mm}$ \\
\hline
\end{tabular}

to the latest GDI literature [19], different combinations were numerically investigated. Tables 4 and $\underline{5}$ show the main specifications for each of the tested cases.

The injected fuel quantities for the specific engine-like conditions were derived from the baseline value on the basis of the Bernoulli equation. The discharge coefficient $\left(c_{d}\right)$ was defined according to Eq.1 [33]

$$
c_{d}=\frac{u_{\text {mean }}}{u_{\text {Bern }}}
$$

and it was assumed as a constant property of the injector with reference to the GM measurements performed on the Spray G geometry for the ECN4 Workshop [22]. The term $u_{\text {mean }}$ represents the average velocity inside the hole under slug flow conditions, while $u_{\text {Bern }}$ is the Bernoulli velocity calculated according to Eq.2:

$$
u_{\text {Bern }}=\sqrt{\frac{2 p_{i n j}}{\rho_{f u e l}}}
$$

TABLE 4 Simulated cases: secondary break-up model,

\begin{tabular}{|c|c|c|c|}
\hline Case & $\begin{array}{l}\text { Secondary } \\
\text { break-up }\end{array}$ & PD [deg] & PCA [deg] \\
\hline Case 1 (ECN) & Reitz-KHRT & 37 & 10 \\
\hline Case 2 (ECN) & Reitz-Diwakar & 37 & 10 \\
\hline Case 3 (ECN) & Reitz-KHRT & 34 & 20 \\
\hline Case 4 & Reitz-KHRT & 37 & 10 \\
\hline Case 5 & Reitz-Diwakar & 37 & 10 \\
\hline Case 6 & Reitz-Diwakar & 37 & 10 \\
\hline Case 7 & Reitz-Diwakar & 37 & 10 \\
\hline Case 8 & Reitz-Diwakar & 37 & 10 \\
\hline Case 9 & Reitz-Diwakar & 37 & 10 \\
\hline Case 10 & Reitz-Diwakar & 37 & 10 \\
\hline Case 11 & Reitz-Diwakar & 37 & 10 \\
\hline Case 12 & Reitz-Diwakar & 37 & 10 \\
\hline
\end{tabular}
"plume direction" and nominal "plume cone angle"

TABLE 5 Simulated cases: operating conditions

\begin{tabular}{|lllll|}
\hline Case & $\left(\boldsymbol{p}_{\text {inj }}\right)[\mathrm{bar}]$ & $\left(\boldsymbol{\rho}_{\text {amb }}\right)\left[\frac{\mathrm{kg}}{\mathrm{m}^{3}}\right]$ & $\left(T_{\text {amb }}\right)[\mathrm{K}]$ \\
\hline Case 1 (ECN) & 200 & 3.5 & 573.15 \\
\hline Case 2 (ECN) & 200 & 3.5 & 573.15 \\
\hline Case 3 (ECN) & 200 & 3.5 & 573.15 \\
\hline Case 4 & 200 & 3.5 & 473.15 \\
\hline Case 5 & 200 & 3.5 & 473.15 \\
\hline Case 6 & 200 & 3.5 & 373.15 \\
\hline Case 7 & 200 & 3.5 & 333.15 \\
\hline Case 8 & 150 & 3.5 & 573.15 \\
\hline Case 9 & 150 & 3.5 & 333.15 \\
\hline Case 10 & 150 & 1.0 & 333.15 \\
\hline Case 11 & 100 & 1.0 & 333.15 \\
Case 12 & 50 & 1.0 & 333.15 \\
\hline
\end{tabular}


TABLE 6 Injected fuel mass for each specific injection pressure

\begin{tabular}{|c|c|}
\hline Injection pressure [bar] & Injected mass [mg] \\
\hline 200 & 10 \\
\hline 150 & 8.66 \\
\hline 100 & 7.07 \\
\hline 50 & 5 \\
\hline
\end{tabular}

FIGURE 5 Mass flow rate profiles scaled according to the injection pressure

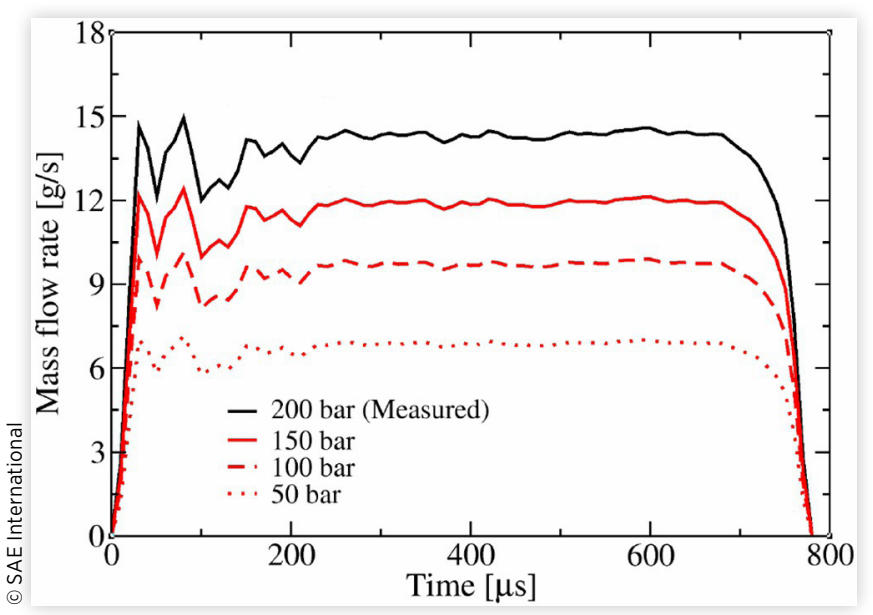

The term $p_{i n j}$ is the injection pressure and $\rho_{f u e l}$ is the density of the liquid fuel under incompressible conditions.

Table 6 reports the achieved values of injected mass compared to the nominal quantity, while Figure 5 shows the different mass flow rate profiles.

Liquid and vapor penetration values were respectively computed as the axial distance from the injector where $99 \%$ of the liquid mass and a mixture fraction of $10^{-3}$ are found.

\section{Atomization: The Huh-Gosman Model}

Primary lagrangian spray parcels are injected in the computational domain with the same diameter of the nozzle holes. The velocity of the injected droplets is function of the adopted mass flow rate profile and the reduction of their diameter is described according to Eq.3:

$$
\frac{d D}{d t}=-C_{5} \frac{L_{a}}{\tau_{a}}
$$

$C_{5}$ is the main constant of the model while $L_{a}$ and $\tau_{a}$ are respectively the characteristic atomization length scale and the characteristic atomization time scale. Initial values of $L_{a}$ and $\tau_{a}$ are used to compute the "plume cone angle" $\alpha$ of the spray of velocity $U$ according to Eq.4:

$$
\tan \left(\frac{\alpha}{2}\right)=\frac{\frac{L_{a}}{\tau_{a}}}{U}
$$

Secondary droplets inherit the velocity from their parents and the atomization process is stopped as soon as either one of the conditions reported in Eq.5 (function of the Weber number We) and Eq.6 (function of the Ohnesorge number Oh) is satisfied [34]:

$$
\begin{gathered}
W e<40 \\
O h>2
\end{gathered}
$$

\section{Secondary Break-Up: The Reitz-KHRT Model}

The Reitz-KHRT is a secondary break-up model which predicts the stripped droplets by using a combination of both the Kelvin-Helmholtz (KH) and Rayleigh-Taylor (RT) instability theories $[35,33]$. Accuracy of the numerical prediciton is increased as the $\mathrm{KH}$ model is applied to the droplets leaving the nozzle, while the RT model, characterized by a faster reduction rate of the droplets size, is applied only beyond a certain distance from the injector. The RT contribution is activated when the wavelength of the fastest growing frequency is smaller than the diameter of the particle, while the $\mathrm{KH}$ break-up starts if the diameter of the particle grows bigger than a reference value which is called stable $\mathrm{KH}$ diameter.

\section{Secondary Break-Up: The Reitz-Diwakar Model}

The Reitz-Diwakar model works by combining the effects of the so-called bag break-up and stripping break-up [36, 37]. The secondary break-up activity is set to start when the value of the Weber number (We) of a parcel grows greater than a so-called $C_{b a g}$ constant, with the stripping phase of the break-up specifically taking place if Eq.7 is satisfied:

$$
\frac{W e}{\sqrt{R e_{d}}}>C_{\text {strip }}
$$

$R e_{d}$ is the droplet Reynolds Number while $C_{\text {strip }}$ is a parameter related to the stripping break-up. Bag break-up is applied if Eq.7 is not satisfied.

\section{Results}

The work was subdivided in three main phases:

1. as a first step, the different combinations of numerical models were validated against the baseline Spray G condition in terms of spray penetration. Afterwards, effects due to changes in "drill angle" and "plume cone angle" were considered with an analysis of the centerline axial velocity and of the velocity profile between plumes;

2. the best numerical combinations were then tested under the baseline injection pressure and ambient density but with decreasing values of ambient temperature $(473.15 \mathrm{~K}, 373.15 \mathrm{~K}$ and $333.15 \mathrm{~K})$ 
allowing for higher spray penetrations. The purpose of the calculations was to assess which secondary break-up model better suits the changes in ambient conditions without requiring a parametric recalibration. The most accurate model was then used for all the other simulations proposed in this work;

3. the numerical set-up was finally validated for a wide range of modern GDI engine-like operating conditions specifically thought for this work, varying from cases with lower injection pressure to lower values of both ambient temperature and ambient density.

\section{Standard ECN Condition: Spray Penetration}

Case 1, Case 2 and Case 3 allowed to study the effects of secondary break-up, "plume direction" and "plume cone angle" under the baseline ECN condition. The accuracy of results was first assessed in terms of liquid and vapor penetration against the well-known results from Parrish et al. [4], while Mie scattering and Schlieren contours were specifically provided for this work by Istituto Motori CNR of Napoli. Figure 6 shows the liquid and vapor penetrations for Case 1 and the comparison with the experimental data. Very similar results were achieved for Case 2 and Case 3.

In terms of liquid penetration, an increase even after the end of injection (EOI) is shown, which is due to few liquid parcels not evaporating and thus still computed as liquid fraction of the fuel. However, since the targeting of the liquid penetration matters only up to the EOI, the results show very good accuracy with the experimental data. While underestimated evaporation between $500 \mu$ s and EOI might happen when dealing with the Spray G injector due to complex plumeto-plume interactions, the reported results show a correct trend for both liquid penetration and evaporation.

With reference to the standard k- $\varepsilon$ turbulence model, it was observed that the value of the $C_{\varepsilon 1}$ constant heavily influences the outcome of spray simulations. For diesel sprays, which are predominantly characterized by a round jet shape of the plumes, a value greater than 1.44 allowed for more

\section{FIGURE 6 Case 1, computed liquid and vapor penetrations}

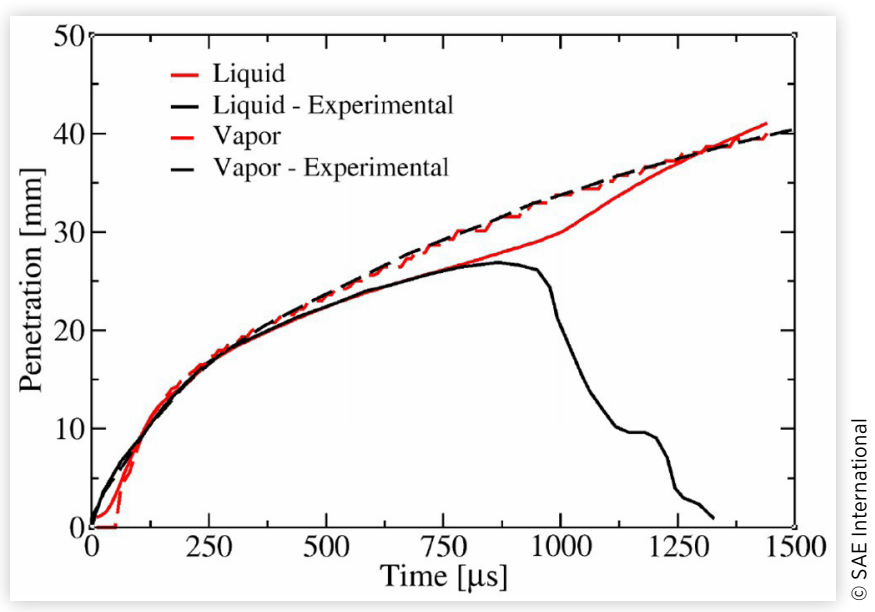

accurate results [ $\underline{38}]$ by mitigating the tendency of the models to overpredict the round jets spreading rate [39]. On the other hand, the jets of GDI sprays are closer and they are thus subjected to a different flow field. As a consequence, a different effect on the spray, due to the changes in value of the $C_{\varepsilon 1}$ parameter, might be observable. In this regard, literature data [17] show that the best results were achieved for values of $C_{\varepsilon 1}$ equal to 1.35 and 1.44, depending on the specific "plume cone angle". It was verified in this work that a value of the constant equal to 1.5 had the effect to increase the penetration of the vapor, especially when coupled with a mesh cell size of $0.5 \mathrm{~mm}$. However it was also observed a steeper liquid penetration curve not capable to reproduce the flattening trend of the experimental data in the range between 500 and $750 \mu \mathrm{s}$. Computed data shown in this paper were thus achieved with a value of 1.44 for the $C_{\varepsilon 1}$ constant.

\section{Standard ECN Condition: Centerline Axial Velocity}

Figure 7 reports a comparison between the axial velocity of Case 1, computed at a distance of $15 \mathrm{~mm}$ from the injector nozzle, and literature experimental PIV measurements and RANS simulations [21].Case 1 shows a recirculation zone which is both faster in its formation and of greater negative velocity (nearly $-9 \frac{m}{s}$ ) if compared to previous RANS results. Case 2 behaved coherently with Case 1 , while the larger spray plumes of Case 3 made the recirculation velocity go beyond a value of $-10 \frac{\mathrm{m}}{\mathrm{s}}$, overcoming the experimental mark. Compared to Case 1 and Case 2, Case 3 was also characterized by a faster collapse of the negative recirculation zone leading to a faster increase of the positive axial velocity after EOI, which was however not enough to compensate the considerably lower negative peak of recirculation velocity. Overall, results from Case 1 and Case 2 matched more consistently the experimental data, but a sensible difference with the experimental trend is observable after $750 \mu$ s, when the computed velocity consistently

FIGURE 7 Case 1, computed axial velocity at $15 \mathrm{~mm}$ from the injector nozzle compared to literature experimental PIV and numerical RANS data [21]

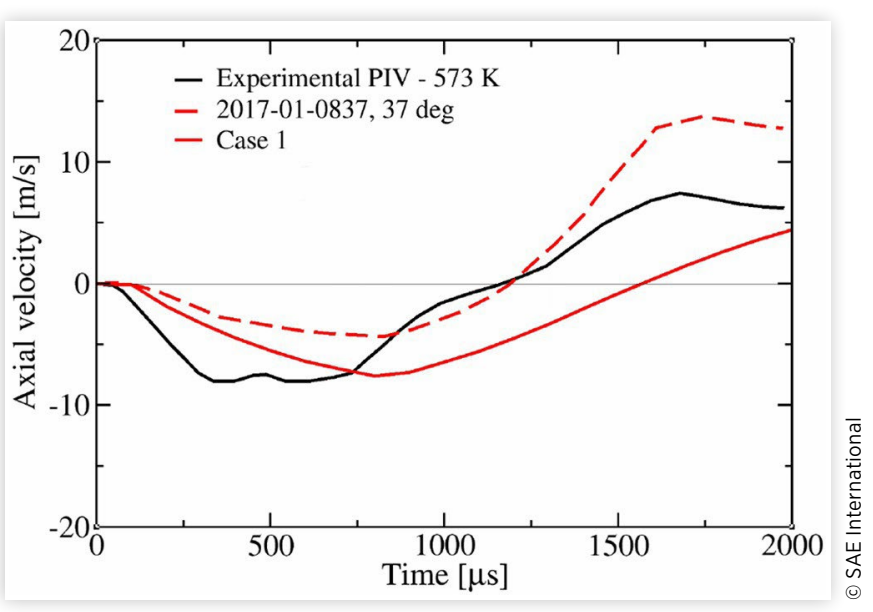

(c) 2018 SAE International. All Rights Reserved. 
FIGURE 8 Case 2, $34^{\circ}$ "plume direction", computed axial velocity at $15 \mathrm{~mm}$ from the injector nozzle compared to literature experimental PIV and numerical RANS data [21]

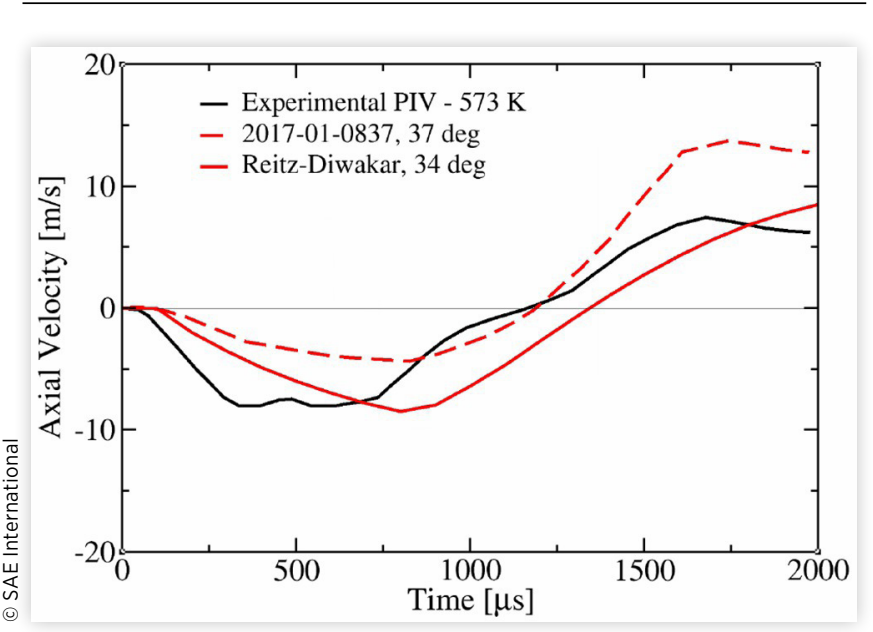

assumes lower values. During the research activity it was better understood that this effect should mainly be related to the "plume direction". Case 2 was thus simulated with a smaller spray angle $\left(34^{\circ}\right.$ instead of $\left.37^{\circ}\right)$ and a positive influence was expected on the behavior of the axial velocity. Figure 8 shows that a better positive velocity trend was reached without losing in accuracy for the prediciton of the negative recirculation, which on the other hand proved to be more influenced by the "plume cone angle" value. While reported literature RANS simulations were charcaterized by a higher positive axial velocity, the results proposed in this work ensured considerably better agreements with the experimental data in terms of spray penetration.

\section{Standard ECN Condition: Axial Velocity Profile between Plumes and Spray Morphology}

To better understand the effects due to plume-to-plume interaction, the axial velocity trend was also analyzed by taking into account its variations with the radial position. According to the experimental convention reported in Figure 9, the numerical results cited in this section were calculated with reference to a "between-plume" orientation, which is characterized by measurements on a radial line rotated by $22.5^{\circ}$ about the $\mathrm{z}$-axis.

Within this context, Figures 10 and 11 show the computed axial velocity contours respectively for Case 1 and Case 3 , scaled in magnitude to the reference experimental Sandia PIV data for which the vertical solid lines indicate the edges of the PIV window.

Both the computed cases were capable to reproduce the overall structure and contour profile of the experimental PIV measurements. Still, some considerable differences must be discussed:

1. with reference to the axial line (radial position at $0 \mathrm{~mm}$ ), it is possible to observe a delayed development of the axial velocity profile over time compared to the experimental data, along with a lower positive peak of axial velocity;
FIGURE 9 Illustration of the adopted experimental "between-plume" plane measurement convention [21]

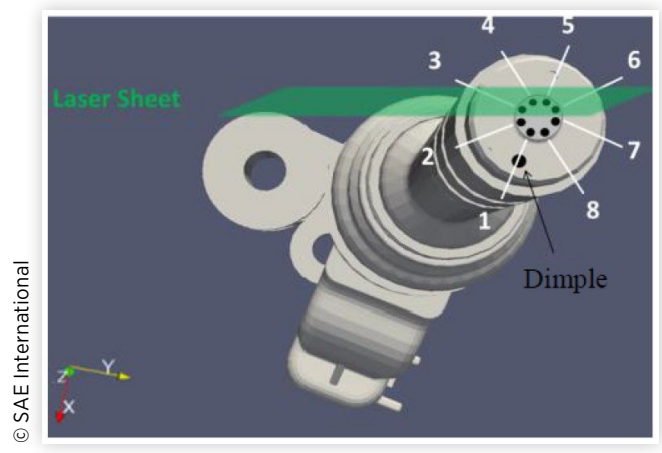

FIGURE 10 Axial velocity contours, experimental PIV [21] against Case 1

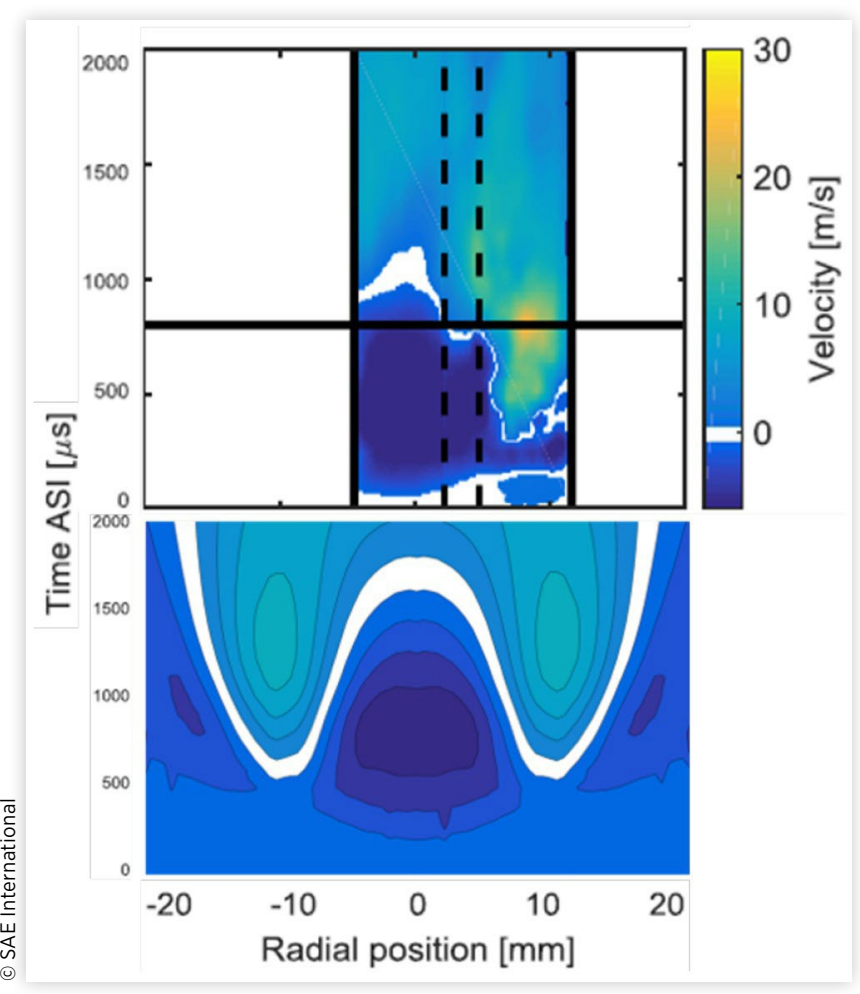

2. at the $10 \mathrm{~mm}$ radial position, which corresponds to an inter-plumes location, experimental data show that zones with zero and then positive velocity begin to develop earlier (at 250-300 $\mu$ s) compared to the numerical results, for which the development happens in the best scenario (Case 1) after $500 \mu \mathrm{s}$.

Furthermore, all the simulated cases are characterized by a lower positive peak of velocity in the inter-plume region compared to experimental results.

The computational domain is characterized by a zero velocity condition before the SOI (quiescent chamber), as it was shown in Figures 7 and $\underline{8}$. 
FIGURE 11 Axial velocity contours, experimental PIV [21] against Case 3

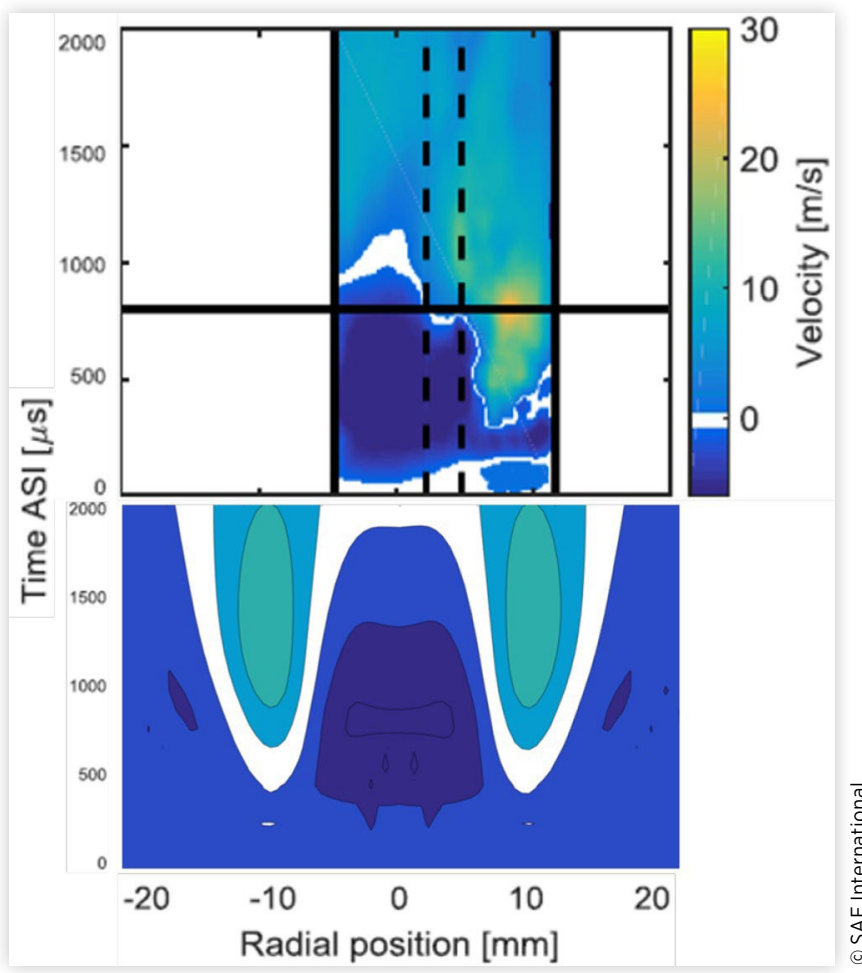

FIGURE 12 Axial velocity contours, experimental PIV [21] against $34^{\circ}$ "plume direction" Case 2

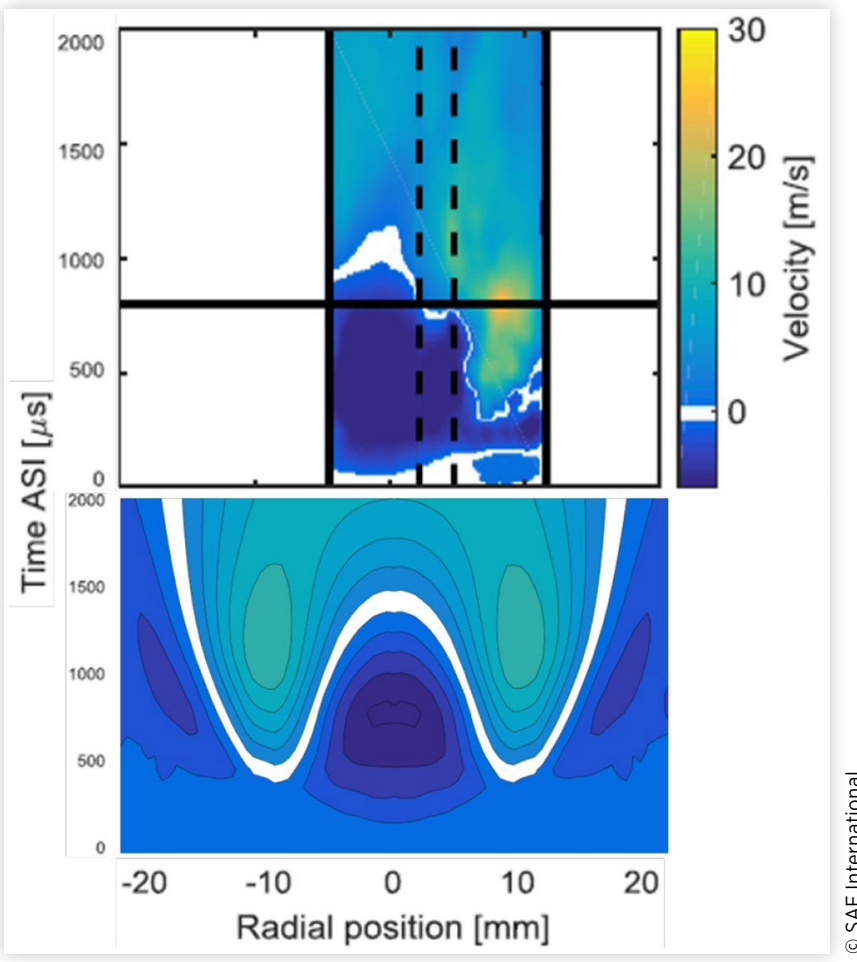

The improvements on the accuracy of the computed axial velocity, observed for Case 2 with a "plume direction" of 34 degrees, can also be inferred when analyzing the radial evolution over time of the velocity contours reported in Figure 12. At the radial position at $0 \mathrm{~mm}$ (which corresponds to the axial line), it is possible to notice that the time after SOI at which the velocity becomes positive is now closer than before to the experimental evidence. This fact also positively influences the peak of velocity magnitude for the $-10 \mathrm{~mm}$ and $10 \mathrm{~mm}$ radial positions, which is now greater than for the previous cases, albeit being still lower than the experimental reference. As a next step, it is clear that to exactly match the experimental axial velocity profile in the domain, the delay during the negative ricirculation between computed results and experimental data must be completely avoided.

$\underline{\text { Figures } 13}, \underline{14}$ and $\underline{15}$ report a comparison between experimental (liquid Mie scattering from Istituto Motori CNR of Napoli) and computed spray morphology evolution (Case 1

FIGURE 13 Spray morphology, experimental against calculated, $160 \mu \mathrm{s}$

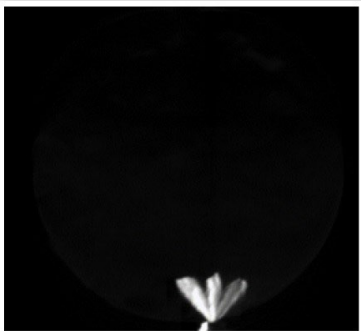

(a) Liquid Mie scattering (b) Computed spray, Case 1

(c) Computed spray, Case 3

FIGURE 14 Spray morphology, experimental against calculated, $560 \mu \mathrm{s}$

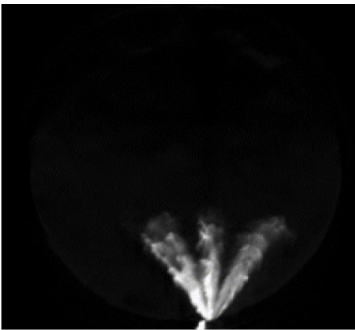

(a) Liquid Mie scattering (b) Computed spray, Case 1

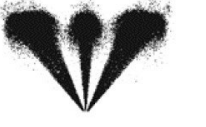

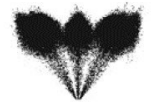

(c) Computed spray, Case 3 
FIGURE 15 Spray morphology, experimental against calculated, $1040 \mu \mathrm{s}$

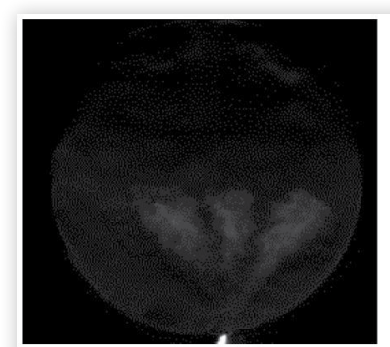

(a) Liquid Mie scattering

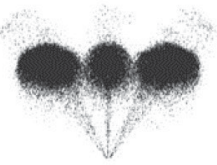

(b) Computed spray, Case 1

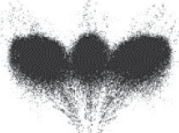

(c) Computed spray, Case 3
FIGURE 16 Comparison between computed spray penetrations for Case 4 and Case 5

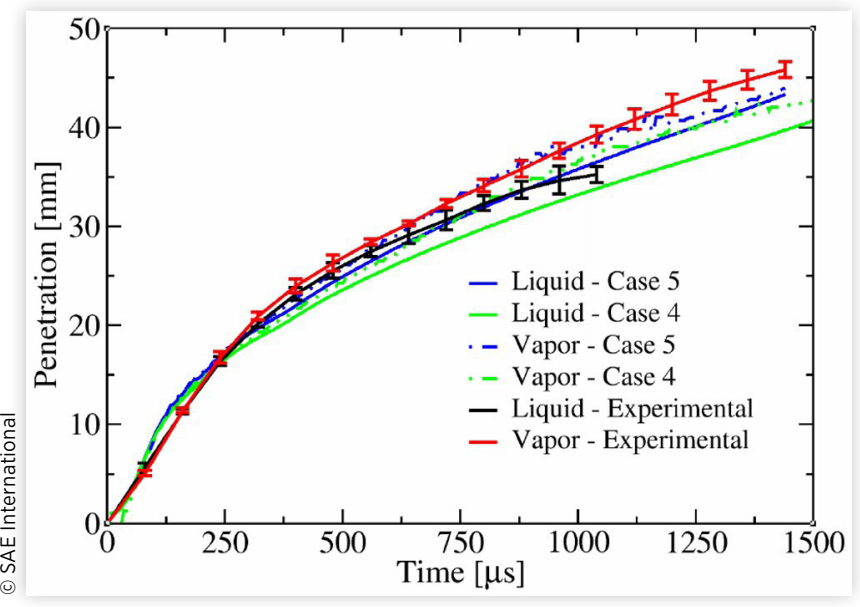

rate. As a consequence, the liquid curve stands below both that of the computed Diwakar case and the experimental, while the vapor curve tends to move closer to that of the Reitz-Diwakar model, mainly after $1000 \mu \mathrm{s}$, when a higher evaporation rate is observable.

Case 5 predicted with good accuracy the size of the stripped parcels, leading to a better estimate of the liquid penetration as a consequence of a reduced rate of evaporation. The Reitz-Diwakar secondary break-up model was thus validated against the remaining engine-like experimental conditions.

Figure 17(b) and 17(c) show that, in addition to Case 5 (Figure 17(a)), the combination of Huh-Gosman and ReitzDiwakar sub-models also provided good results for the cases with ambient temperature of $373.15 \mathrm{~K}$ and $333.15 \mathrm{~K}$. Case 5, Case 6 and Case 7 were characterized by a cell size of $0.5 \mathrm{~mm}$ for the computational grid.

\section{Engine-Like Conditions: Case 8 and Case 9}

An injection pressure of 150 bar, the baseline ECN ambient density and two values of ambient temperature equal to 573.15 K (Figure 18(a)) and 333.15 K (Figure 18(b)) were tested in this section.

The liquid curve of Case 8 matches the experimental data, with the vapor trend which is also reproduced with a good level of accuracy.

Figure 18(b) demonstrates the strong influence of the reduced ambient temperature on the liquid penetration, whose average experimental value, at $1000 \mu \mathrm{s}$ after SOI, is about $50 \%$ greater than for the case at $573.15 \mathrm{~K}$. The predicted liquid curve fits the experimental range with just a slight overprediction observable for time-steps approaching the end of the simulation. Given the low evaporating ambient conditions, the computed vapor and liquid penetrations were similar, however such aspect is also characteristic of the experimental measurements. 
FIGURE 17 Spray penetration values, Case 5, Case 6 and Case 7

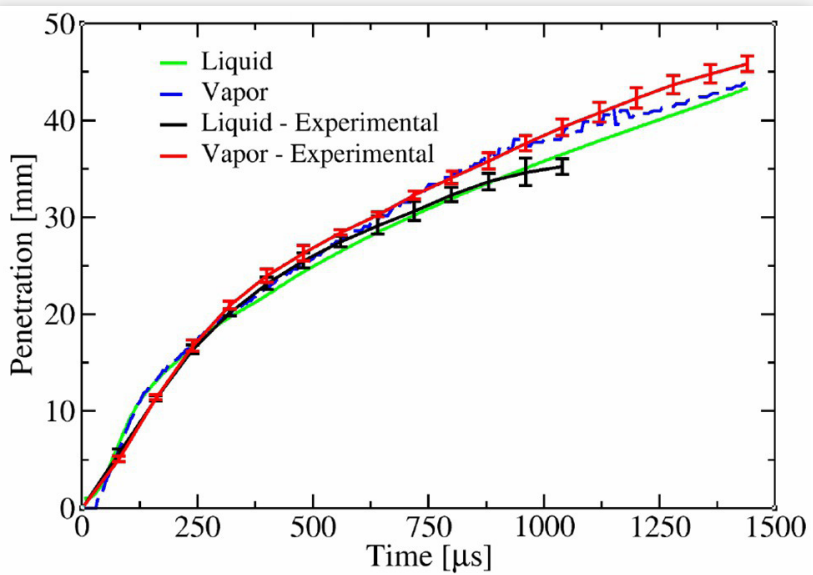

(a) Computed spray penetration, Case 5

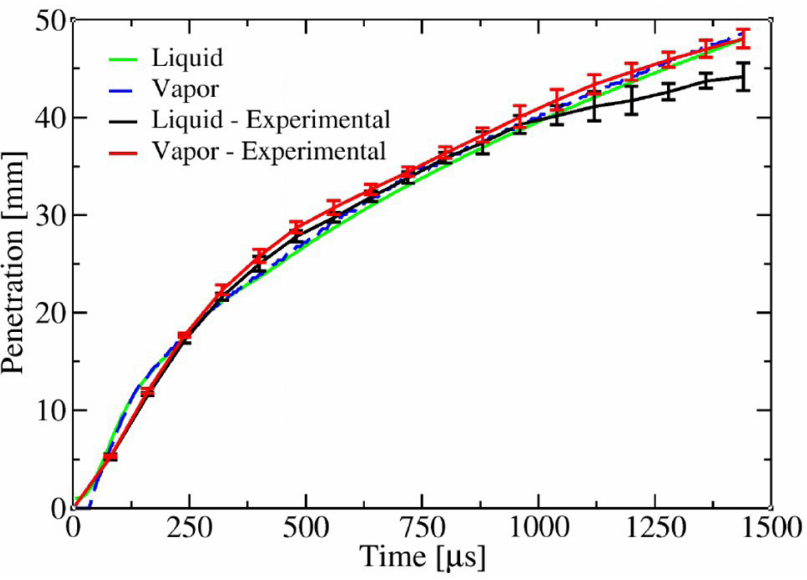

(b) Computed spray penetration, Case 6

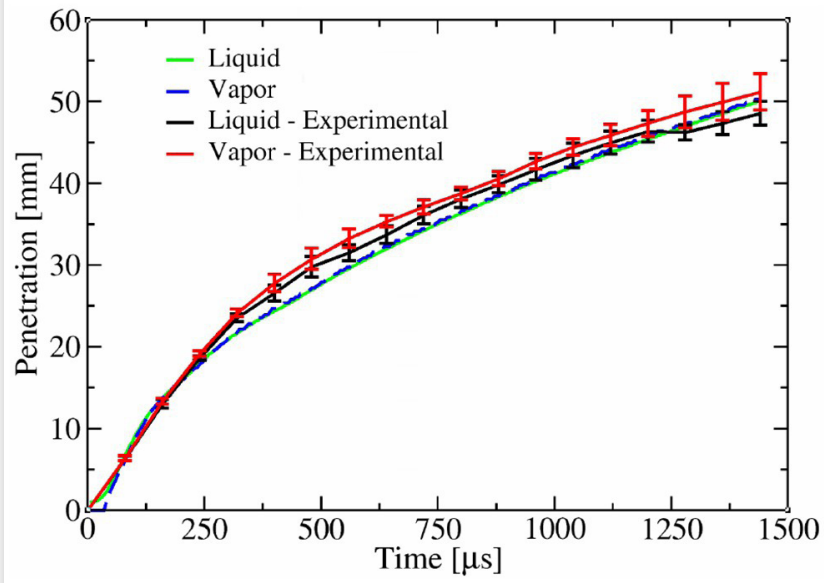

(c) Computed spray penetration, Case 7

\section{Engine-Like Conditions: Case 10, Case 11 and Case 12}

The last part of the work was focused on the simulation of the less evaporative cases, characterized by a decreasing injection pressure along with the lowest values of ambient density and temperature. As a consequence of the cold environment

\section{FIGURE 18 Spray penetration values, Case 8 and Case 9}

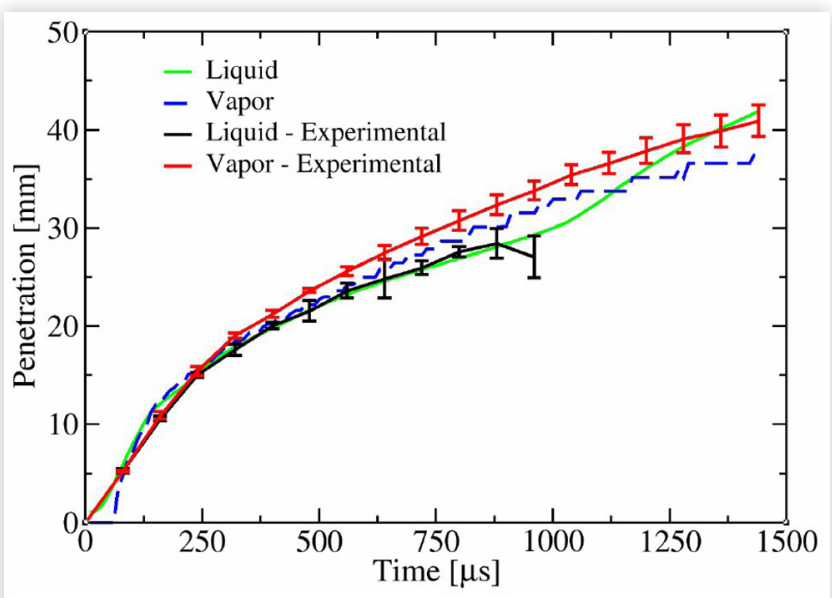

(a) Computed spray penetration, Case 8

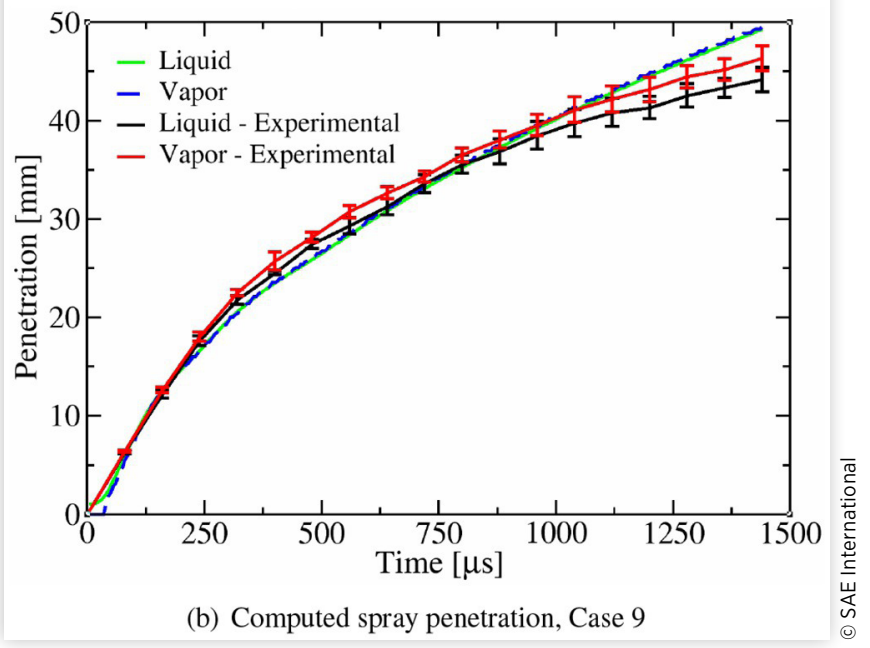

and because of low ambient density reducing drag and opposition to the penetration of the spray, an almost completely inhibited evaporation was expected. Figure 19(a), 19(b) and 19 (c) report the calculated liquid and vapor penetrations. The adopted minimum cell size was equal to $1 \mathrm{~mm}$. It was previously verified that the Reitz-Diwakar secondary break-up model could predict liquid and vapor penetrations under different operating conditions with no changes required in the baseline numerical set-up. On this basis, the limits of such approach were then stressed with consistent decreases of ambient temperature and density. The effectiveness of the proposed numerical combination was once again proven, since even the experimental data of the less evaporative conditions were matched. Furthermore, unlike other secondary break-up models, Reitz-Diwakar required almost no parametric recalibration to provide good spray penetration results even under conditions of limited evaporation. In this regard, it was only necessary to decrease the $C_{b a g}$ parameter, which allows for the activation of the secondary break-up when its value is lower than the Weber Number of the parcel. The selected value of $C_{b a g}$ was then kept constant and equal for Case 10, Case 11 and Case 12.

A robust numerical set-up (Tables 7 and $\underline{8}$ ) could thus be defined for RANS multi-hole GDI simulations using the 
FIGURE 19 Spray penetration values, Case 10, Case 11 and Case 12

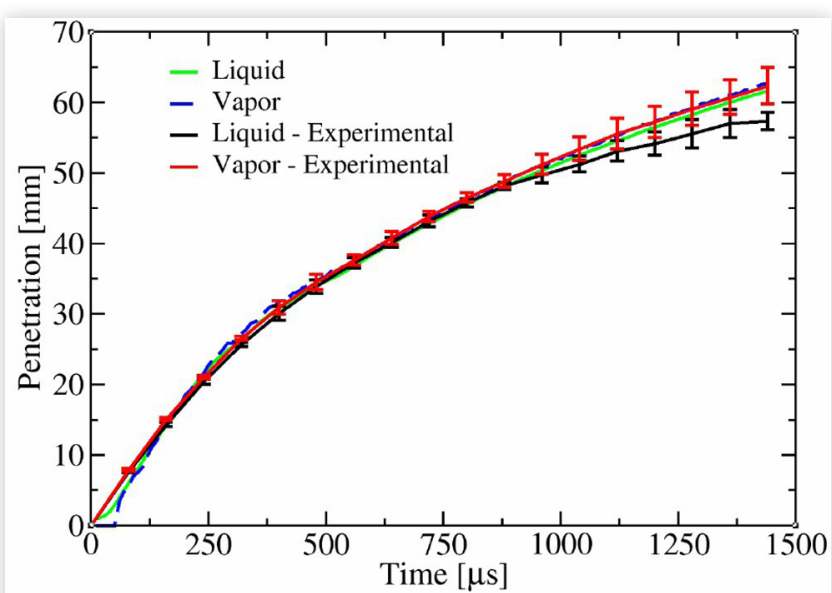

(a) Computed spray penetration, Case 10

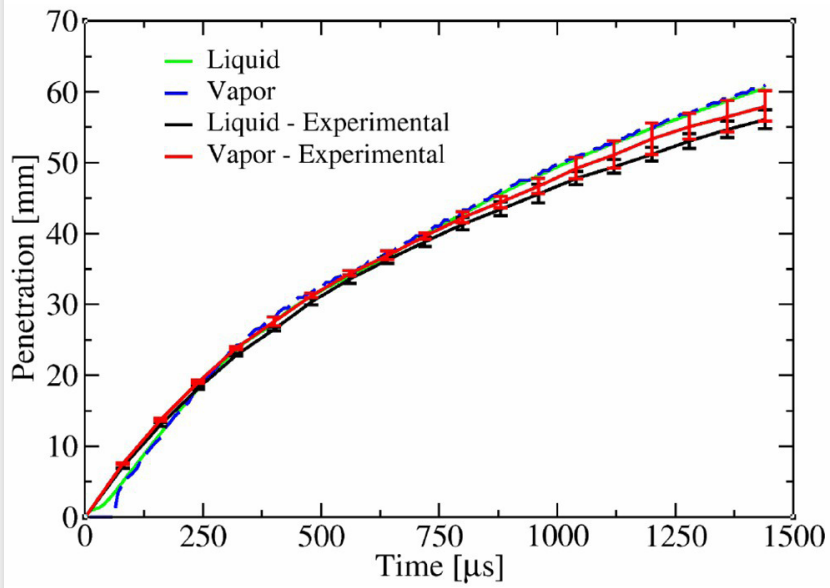

(b) Computed spray penetration, Case 11

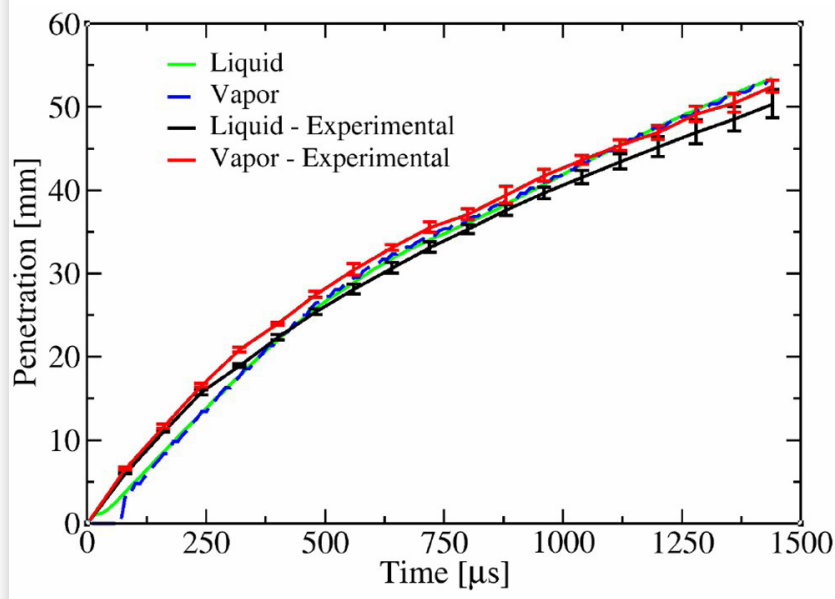

(c) Computed spray penetration, Case 12

Reitz-Diwakar sub-model coupled with Huh-Gosman for atomization.

Overall, the computed liquid and vapor penetrations coherently fit the experimental range, with only a slight difference for Case 12 just after the SOI. However, given the almost non-evaporating condition of the spray, such discrepancy can be considered negligible.
TABLE 7 Constanst adopted for the Huh-Gosman model

\begin{tabular}{|l|l|}
\hline Constant & Value \\
\hline Kc & 0.45 \\
\hline Keps & 0.1 \\
C1 & 2.0 \\
C2 & 0.5 \\
C3 & 0.95 \\
C4 & 0.38 \\
\hline Ca1 & 0.082 \\
Ca2 & 0.457 \\
\hline WeLimit & 0.25 \\
\hline
\end{tabular}

TABLE 8 Constanst adopted for the Reitz-Diwakar model

\begin{tabular}{|l|l|}
\hline Constant & Value \\
\hline Cbag (Case 2, Cases 5-9) & 12 \\
\hline Cbag (Cases 10-11-12) & 0.5 \\
\hline Cstrip & 0.5 \\
Cb & 1.0 \\
Cs & 4.1
\end{tabular}

Figures $20, \underline{21}$ and $\underline{22}$ finally report a morphological comparison between the experimental liquid phase captured with a Mie scattering tecnique and the computed spray of Case 12. Images are for times after SOI respectively equal to $160 \mu \mathrm{s}$, $560 \mu \mathrm{s}$ and $1040 \mu \mathrm{s}$.

Results are consistent with the experimental data and the previously observed tendency of the computed plumes to

FIGURE 20 Spray morphology, experimental against calculated, $160 \mu \mathrm{s}$

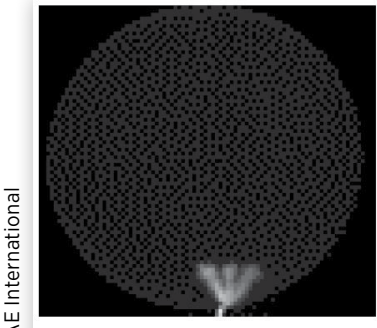

(a) Liquid Mie scattering (b) Computed spray, Case 12
FIGURE 21 Spray morphology, experimental against calculated, $560 \mu \mathrm{s}$

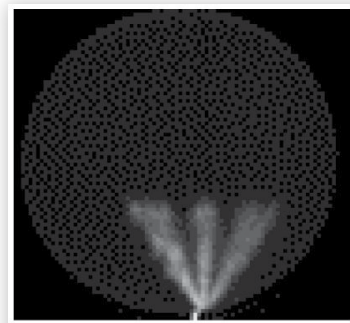

(a) Liquid Mie scattering

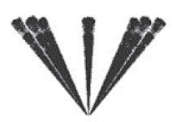

(b) Computed spray, Case 12 
FIGURE 22 Spray morphology, experimental against calculated, $1040 \mu \mathrm{s}$

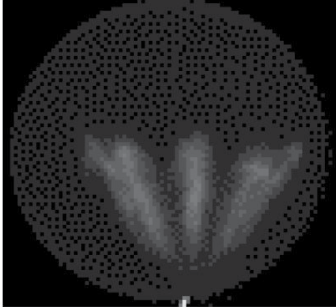

(a) Liquid Mie scattering

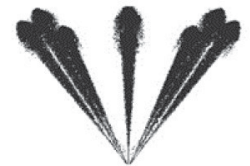

(b) Computed spray, Case 12 ஸิ assume a round jet shape is considerably reduced due to the more inhibited evaporating conditions. Furthermore, as expected, low values of ambient temperature and density led to a decrease of the "plume cone angle" for both the experimental and the computed spray jets.

\section{Spray Penetration at $1040 \mu \mathrm{S}$ and SMD Analysis}

Figure 23(a) and 23(b) respectively show values of spray penetration as a function of the injection pressure and of the ambient temperature. A simulation time of $1040 \mu$ s was chosen because it could approximate the average duration of the injection process for GDI engines under full power conditions, for which it is mandatory to accurately assess the air-fuel mixing process to ensure a stable and efficient combustion. Overall, good accuracy with the experimental range of validity for both the liquid and vapor phases was achieved. More in detail, the less evaporative (Figure 23(a)) and the $473.15 \mathrm{~K}$ ambient temperature (Figure 23(a)) cases displayed a slight overestimation of the liquid penetration, which could however be considered negligible.

With reference to accurate literature researches performed on GDI sprays [40], Figure 24 reports the computed values of Sauter Mean Diameter (SMD) [33] for each of the tested cases and it compares them with experimental data for a modern GDI injector proposed by Hammer et al. [41]. The computed results are consistent with the experimental range and they reproduce with good accuracy the expected trend of increasing droplet diameter with the reduction of the injection pressure.

A representation of the evolution of the droplets diameter for the less evaporating case is finally reported in Figure 25(a) and 25(b), respectively for times of $1040 \mu \mathrm{s}$ and $1440 \mu \mathrm{s}$ after SOI.

\section{Conclusions}

A RANS approach capable to reproduce with good accuracy the behavior of a multi-hole GDI spray (ECN Spray G injector) under different engine-like operating conditions was extensively investigated in this work. Effects of changes in "plume direction" and "plume cone angle" were considered, along
FIGURE 23 Computed spray penetrations respectively function of injection pressure and ambient temperature

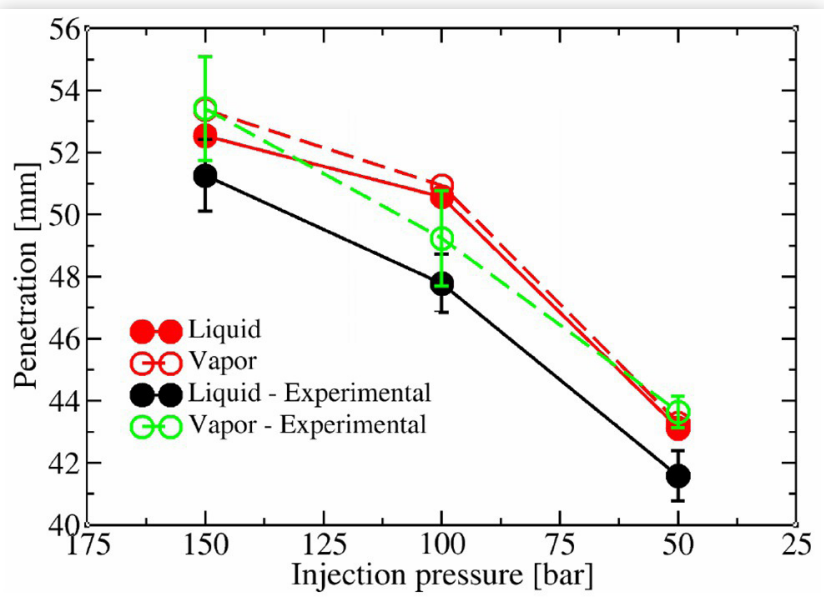

(a) Computed spray penetrations at $1040 \mu \mathrm{s}$ after SOI for cases at constant ambient temperature $(333.15 \mathrm{~K})$ and density $\left(1.0 \frac{\mathrm{kg}}{\mathrm{m}^{3}}\right)$

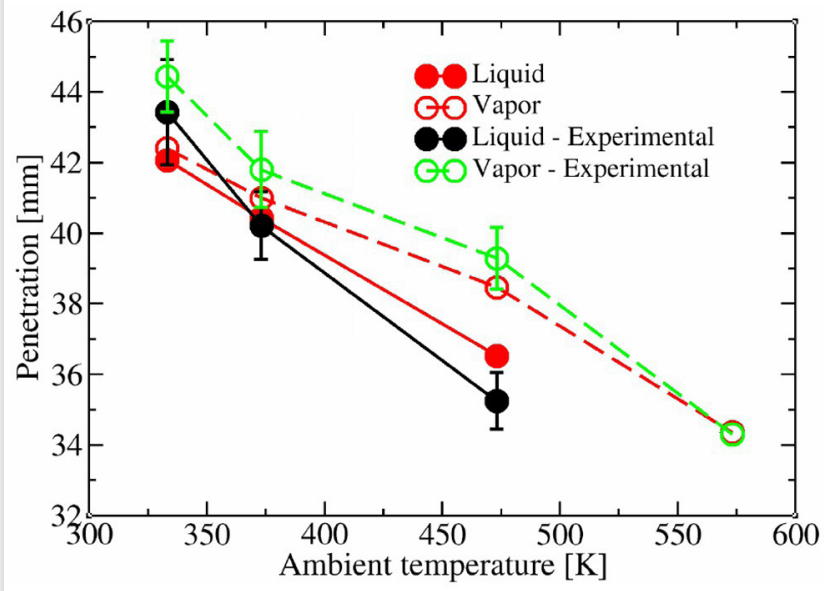

(b) Computed spray penetrations at $1040 \mu \mathrm{s}$ after SOI for cases at constant injection pressure (200 bar) and ambient density $\left(3.5 \frac{\mathrm{kg}}{\mathrm{m}^{3}}\right)$

FIGURE 24 Comparison between computed SMD and experimental data [41]

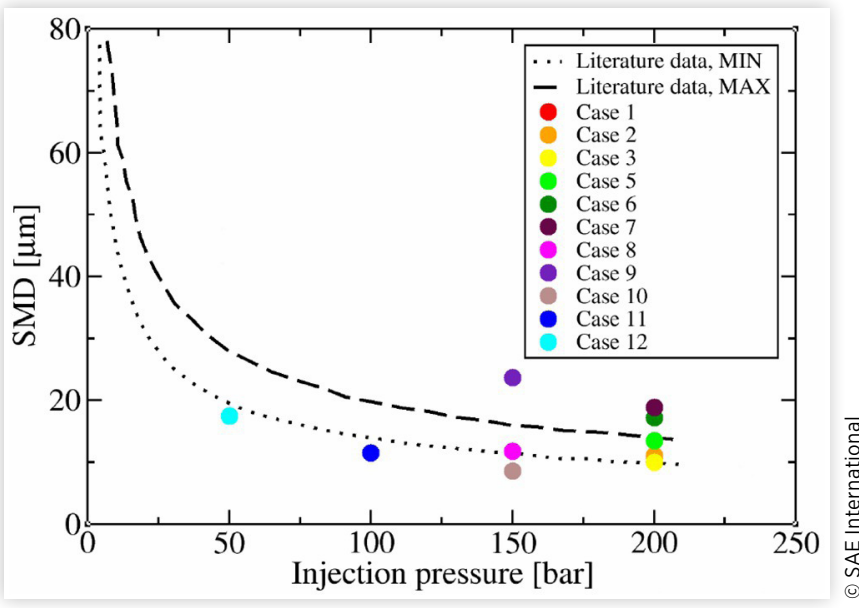

(c) 2018 SAE International. All Rights Reserved. 
FIGURE 25 Case 12, evolution of droplets diameter for different times after SOI

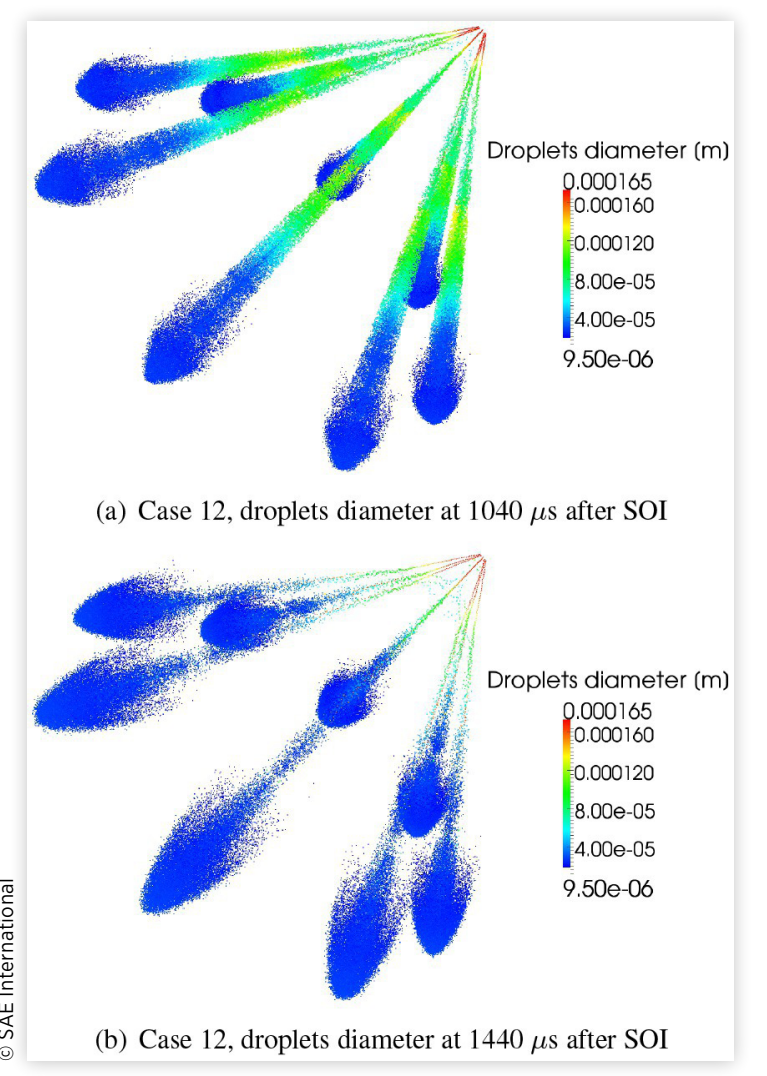

with different combinations of atomization and secondary break-up sub-models. Each proposed numerical set-up was calibrated and validated under the baseline ECN Spray G condition against literature data for liquid and vapor penetration, centerline recirculation velocity and radial evolution of the axial velocity profile over time. Computed spray morphology was compared with experimental images provided by Istituto Motori CNR of Napoli. Spray penetrations were correctly predicted by the models, with the best numerical set-up (Huh-Gosman for atomization and ReitzDiwakar for secondary break-up) capable to also improve the computed negative axial recirculation velocity and radial contours of the axial velocity over time. However, a delay of the computed positive part of the axial velocity curve was observed, along with a lower peak in magnitude. As a consequence, the morphology of the computed spray plumes was characterized, towards EOI, by a more rounded jet profile if compared to the experimental Mie scattering data. A more detailed investigation of such phenomena will be the main focus of future research activities.

A wide range of engine-like operating points, specifically thought for this work, was fundamental to stress the most accurate numerical set-up among those calibrated under the baseline ECN condition. By testing different combinations of ambient temperature, density and injection pressure it was possible to identify the most suitable set of spray sub-model constants. It was observed that a decrease of injection pressure and ambient temperature hardly influenced the accuracy of the proposed set-up. For Case 2 and for Cases from 5 to 9 , good results were indeed achieved with the same parametric calibration validated under the baseline ECN condition. Modifications of the spray secondary break-up sub-model parameters were necessary only for cases with the lowest tested values of ambient density $\left(1.0 \frac{\mathrm{kg}}{\mathrm{m}^{3}}\right)$ and ambient temperature $(333.15 \mathrm{~K})$. Specifically, the $C_{b a g}$ parameter of the Reitz-Diwakar model was decreased to counterbalance the conditions of considerably reduced evaporation and, once a fitting value was identified, it was kept constant and equal for all the low-evaporating cases. While the numerical set-up based on the Reitz-Diwakar model allowed to achieve encouraging results, future research activities on the Spray G geometry could be focused on a more detailed coupling of nozzle flow and spray simulations to improve the prediction of recirculation and plume-to-plume interaction, also with a specific comparison between experimental and computed values of SMD. Furthermore, focus could be put on a comprehensive analysis of the characteristic phenomena of the flash boiling condition.

\section{Contact Information}

PhD student Davide Paredi

Department of Energy, Politecnico di Milano

Via Lambruschini, 4

20156 Milano, Italy

davide.paredi@polimi.it

\section{References}

1. Koch, P., Loffler, M.G., Wensing, M., and Leipertz, A., "Study of the Mixture Formation Processes inside a Modern Direct Injection Gasoline Engine," International Journal of Engine Research 11:455-471, 2010, doi:10.1243/14680874JER606.

2. Zeng, W., Sjoberg, M., and Reuss, D.L., "Combined Effects of Flow/Spray Interactions and EGR on Combustion Variability for a Stratified DISI Engine," Proceedings of the Combustion Institute 35(3):2907-2914, 2015.

3. Zeng, W., Sjoberg, M., Reuss, D.L., and Hu, Z., "The Role of Spray-Enhanced Swirl Flow for Combustion Stabilization in a Stratified Charge DISI Engine," Combustion and Flame 168:, 166 to 185, June 2016.

4. Parrish, S., "Evaluation of Liquid and Vapor Penetration of Sprays from a Multi-Hole Gasoline Fuel Injector Operating under Engine-Like Conditions," SAE Int. J. Engines 7(2):10171033, 2014, doi:10.4271/2014-01-1409.

5. Zhao, F., Harrington, D.L., and Lai, M.-C.D., Automotive Gasoline Direct Injection Engines. Society of Automotive Engineers, Inc., Warrendale, PA, ISBN:978-0-7680-0882$1,2002$.

6. Park, S.W., Kim, H.J., and Lee, C.S. An Experimental and Numerical Study on Atomization Characteristics of Gasoline Injector for Direct Injection Engines. 15th Annual Conference on Liquid Atomization and Spray Systems, Madison, May 2002. 
7. Fansler, T.D., Drake, M.C., Gajdeczko, B., Duwel, L. et al., "Quantitative Liquid and Vapor Distribution Measurements in Evaporating Fuel Sprays Using Laser-Induced Exciplex Fluorescence," Meas. Sci. Technol. 20:125401, 2009, doi:10.1088/0957-0233/20/12/125401.

8. Parrish, S.E., Zhang, G., and Zink, R.J., "Liquid and Vapor Envelopes of Sprays from a Multi-Hole Fuel Injector Operating under Closely-Spaced Double-Injection Conditions," SAE Int. J. Engines 5(2):400-414, 2012, doi:10.4271/2012-01-0462.

9. Blessinger, M., Meijer, M., Pickett, L.M. et al., "Liquid/Vapor Penetration and Plume-Plume Interaction of Vaporizing Iso-Octane and Ethanol SIDI Sprays," 25th Annual Conference on Liquid Atomization and Spray Systems, Pittsburg, May 2013.

10. Sphicas, P., Pickett, L.M., Skeen, S.A., and Frank, J.H., "InterPlume Aerodynamics for Gasoline Spray Collapse," Int. J. Engine Research, 2016, 2016, Submitted.

11. Itani, L.M., Bruneaux, G., Hermant, L., and Schulz, C., "Investigation of the Mixing Process and the Fuel Mass Concentration Fields for a Gasoline Direct-Injection Spray at ECN Spray G Conditions and Variants," SAE Technical Paper 2015-01-1902, 2015, doi:10.4271/2015-01-1902.

12. Parrish, S.E. and Zink, R.J., "Spray Characteristics of MultiHole Injectors under Flash Boiling Conditions," ILASS Americas 2008, 2008.

13. Zeng, W., Xu, M., Zhang, G., Zhang, Y. et al., "Atomization and Vaporization for Flash-Boiling Multi-Hole Sprays with Alcohol Fuels," Fuel 95:28797, 2012.

14. Saha, K., Som, S., Battistoni, M., Li, Y. et al., "Numerical Investigation of Two-Phase Flow Evolution of In- and NearNozzle Regions of a Gasoline Direct Injection Engine during Needle Transients," SAE Int. J. Engines 9(2):1230-1240, 2016, doi:10.4271/2016-01-0870.

15. Moulai, M., Grover, R., Parrish, S., and Schmidt, D., "Internal and Near-Nozzle Flow in a Multi-Hole Gasoline Injector under Flashing and Non-Flashing Conditions," SAE Technical Paper 2015-01-0944, 2015, doi:10.4271/2015-01-0944.

16. Baldwin, E.T., Grover, R., Parrish, S.E., Duke, D.J. et al., "String Flash-Boiling in Gasoline Direct Injection Simulations with Transient Needle Motion," Int. J. Multiphase Flow 87:90-101, 2016.

17. Saha, K., Quan, S., Battistoni, M., Som, S. et al., “Coupled Eulerian Internal Nozzle Flow and Lagrangian Spray Simulations for GDI Systems," SAE Technical Paper 2017-010834, 2017, doi:10.4271/2017-01-0834.

18. Rutland, C.J., "Large-Eddy Simulations for Internal Combustion Engines - A Review," International Journal of Engine Research 12:421-451, 2011, doi:10.1177/1468087411407248.

19. Bode, M., Falkenstein, T., Le Chenadec, V., Kang, S. et al., “A New Euler/Lagrange Approach for Multiphase Simulations of a Multi-Hole GDI Injector," SAE Technical Paper 2015-010949, 2015, doi:10.4271/2015-01-0949.

20. Payri, R., Salvador, F.J., Mart-Aldarav, P., and Vaquerizo, D., "ECN Spray G External Spray Visualization and Spray Collapse Description through Penetration and Morphology Analysis," Applied Thermal Engineering 112:304-316, 2017, doi:10.1016/j.applthermaleng.2016.10.023.
21. Sphicas, P., Pickett, L., Skeen, S., Frank, J. et al., "A Comparison of Experimental and Modeled Velocity in Gasoline Direct-Injection Sprays with Plume Interaction and Collapse," SAE Int. J. Fuels Lubr. 10(1):184-201, 2017.

22. https://ecn.sandia.gov/ecn-workshop/ecn4-workshop/.

23. Manin, J., Jung, Y., Skeen, S.A., Pickett, L.M. et al., "Experimental Characterization of DI Gasoline Injection Processes," SAE Technical Paper 2015-01-1894, 2015, doi:10.4271/2015-01-1894.

24. Strek, P., Duke, D., Swantek, A., Kastengren, A. et al., "X-Ray Radiography and CFD Studies of the Spray G Injector," SAE Technical Paper 2016-01-0858, 2016, doi:10.4271/2016-01$\underline{0858}$.

25. Payri, R., Gimeno, J., Marti-Aldaravi, P., and Vaquerizo, D., "Momentum Flux Measurements on an ECN GDI Injector," SAE Technical Paper 2015-01-1893, 2015, doi:10.4271/201501-1893.

26. Allocca, L., Montanaro, A., Di Gioia, R., and Bonandrini, G., "Spray Characterization of a Single-Hole Gasoline Injector under Flash Boiling Conditions," SAE Technical Paper 201432-0041, 2014, doi:10.4271/2014-32-0041.

27. Montanaro, A., Allocca, L., and Lazzaro, M., "Iso-Octane Spray from a GDI Multi-Hole Injector under Non- and Flash Boiling Conditions," SAE Technical Paper 2017-012319, 2017.

28. Subramaniam, S., "Lagrangian/Eulerian Methods for Multiphase Flows," Department of Mechanical Engineering, Iowa State University.

29. Huh, K.Y. and Gosman, A.D., "A Phenomenological Model of Diesel Spray Atomization," Proceedings of the International Conference on Multiphase Flows, Tsukuba, 1991.

30. Huh, K.Y., Lee, E., and Koo, J., "Diesel Spray Atomization Model Considering Nozzle Exit Turbulence Conditions," Atomization and Spray 8(4):453-469, 1998.

31. Reitz, R.D., "Modeling Atomization Processes in High Pressure Vaporizing Sprays," Atomization and Spray Technology 3:309-337, 1987.

32. Reitz, R.D. and Diwakar, R., "Structure of High-Pressure Sprays," SAE Technical Paper $\underline{870598}$, 1987, doi: $10.4271 / 870598$.

33. Baumgarten, C., "Mixture Formation in Internal Combustion Engines," (Springer).

34. Faeth, G.M., Hsiang, L.P., and Wu, P.K., "Structure and Breakup Properties of Sprays," Int. J. Multiphase Flow 21:99127, 1995.

35. Stiesch, G., "Modeling Engine Spray and Combustion Processes," (Springer).

36. Pilch, M., and Erdman, C.A., "Use of Breakup Time Data and Velocity History Data to Predict the Maximum Size of Stable Fragments for Acceleration-Induced Breakup of a Liquid Drop," Int. J. Multiphase Flow 13, 1987(6):741757, 1987.

37. Jeong, S.J., Oh, S.D., Lee, H.K., Park, J.K. et al., "Research and Development of a 2.9 Liter Light-Duty DME Truck Using Common Rail Fuel Injection System," KSAE 2011 Annual Conference, KSAE11-A0073, 2011. 
38. Torelli, R., D’Errico, G., Lucchini, T., Ikonomou, V., and McDavid, R.M., "A Spherical Volume Interaction DDM Approach for Diesel Spray Modeling," Atomization and Sprays 25(4):335-374, 2015.

39. Garcia-Oliver, J., Pastor, J., Pandal, A., Trask, N. et al., "Diesel Spray CFD Simulations Based on the $\Sigma$-y Eulerian Atomization Model," Atomization and Sprays 23:71-95, 2013.

40. Lucchini, T., D’Errico, G., Onorati, A., Bonandrini, G. et al., "Development and Application of a Computational Fluid Dynamics Methodology to Predict Fuel-Air Mixing and
Sources of Soot Formation in Gasoline Direct Injection Engines," International Journal of Engine Research, 2013, doi: $10.1177 / 1468087413500297$.

41. Hammer, J., Kufferath, A., and Wehmeier, K., "Modern GDI Combustion Systems with Focus on Fuel Metering Technology Fulfilling Future Emission Legislation," SIA Conference: The Spark ignition Ingine of the Future, Strasbourg, 30 Nov-1 Dec 2011.

All rights reserved. No part of this publication may be reproduced, stored in a retrieval system, or transmitted, in any form or by any means, electronic, mechanical, photocopying, recording, or otherwise, without the prior written permission of the copyright holder.

Positions and opinions advanced in this paper are those of the author(s) and not necessarily those of SAE International. The author is solely responsible for the content of the paper.

ISSN 0148-7191 